\title{
¿Una ética sin obligaciones universales? Rorty y los derechos humanos
}

\author{
JOSÉ MANUEL PANEA MÁRQUEZ \\ Universidad de Sevilla
}

\section{Introducción}

Para abordar la pregunta que da título a nuestro trabajo, vamos a centrarnos en el análisis que sobre dicha cuestión realiza el pragmatista Richard Rorty, y ello porque nos brinda un planteamiento muy interesante aunque, a nuestro parecer, no menos discutible. Pues bien, como el propio Rorty se ha autodefinido, su filosofía cabe enmarcarla dentro de lo que actualmente se conoce como pensamiento débir. $\mathrm{Y}$ a decir verdad, nos acercamos a este autor como a cualquier otro, a saber, con la esperanza de que sus ideas satisfagan una doble demanda, teórica y práctica a un tiempo: por una parte, queremos comprender mejor, encontrar un conjunto de respuestas filosóficas a los problemas que más nos conciernen: la verdad, la supuesta naturaleza humana, el lenguaje, la moral, etc. Pero, por otra parte, esperamos encontrar en tales indagaciones una aclaración, una luz que nos sea de utilidad para construir nuestro presente y futuro. Lamentablemente tenemos que reconocer nuestra personal decepción con las expectativas que la vía Rorty parecía prometer.

La pregunta con la que abriamos esta reflexión, a saber, '¿una ética sin obligaciones universales?' no hace sino cuestionar el título del tercer capítulo de su libro: ¿Esperanza o conocimiento? Una introducción al pragmatismo ${ }^{2}$. Con dicho cuestionamiento pretendemos mostrar el talante del presente estudio: dialogar críticamente con Rorty a partir de sus textos. En primer lugar, pues, esbozaremos las líneas maes- tras que definen su pensamiento. $Y$, en segundo lugar, veremos una aplicación del mismo: cómo afronta Rorty la problemática de los derechos humanos. Será desde esta cuestión desde donde proyectaremos nuestras dudas acerca de si lo que el pragmatismo de Rorty pretende puede lograrse con las armas filosóficas de las que dispone.

\section{Un mundo sin esencias}

Pues bien, para Rorty estamos en un mundo sin esencias ${ }^{3}$. Para el pragmatista, no podemos ubicarnos fuera del lenguaje, fuera de la mediación lingüística. Es algo que hemos aprendido de Wittgenstein y Heidegger, Por ello, hemos de desconfiar de la distinción griega entre apariencia y realidad. Todo conocimiento es una descripción que resulta adecuada para nuestros propósitos sociales (Foucault). EI platonismo proponía librarse del nomos, de la convención, y volverse a la physis. Pero para el pragmatista, la distinción physis-nomos, realidad-apariencia, se desvanece, porque toda aprehensión es una descripción en función de las necesidades sociales, y 'naturaleza' o 'realidad' son expresiones de algo no cognoscible. En definitiva, concluye Rorty, “(...) es preciso convencerse de que la búsqueda en la que se empeñó $\mathrm{Pla}-$ tón, el intento de ir de la apariencia a la naturaleza intrínseca de la realidad es vana." 4 Para el pragmatista se quiebra la distinción extrínseco-intrínseco. No podemos escapar a nuestras necesidades, a 
nuestra conciencia, a nuestro lenguaje. Pero no hay un 'en sí' de las cosas. Pues bien, si Rorty tiene razón, carecería de sentido preguntarse por lo intrinsecamente humano, bestial, arbitrario, monstruoso, o cruel. Vivimos en un mundo relacional, sin esencias ni substancias. A Rorty, hablar de 'esencia' y de 'relacional' le parecen dos modos antitéticos e irreconciliables de hablar. Mas esta nos parece una de las limitaciones de su planteamiento, porque creemos posible el esfuerzo de definir la crueldad, el bestialismo, el engaño, la tortura, por supuesto, sin salirnos de nuestro lenguaje, y lograr un amplio acuerdo. Negar tal posibilidad nos convierte en esos disputantes deshonestos de los que hablaba Hume al comienzo de sus Investigaciones sobre los principios de la moral, que, negando toda clase de distinciones morales, discuten por el mero placer de discutir ${ }^{5}$. De manera que, volviendo a Rorty, como no hay esencias, solo relaciones contingentes (como si la noción de esencia excluyera forzosamente lo relacional) tampoco cabe hablar de 'lo humano'. No hay algo inalterable llamado 'lo humano' y que nos diferencie del resto del universo. "El pragmatismo deja a un lado esa suposición e insta a considerar que la noción de humanidad carece de limites fijos, que la palabra 'humano' nombra un proyecto impreciso pero prometedor, no una esencia." ${ }^{\text {" }}$ No cabe duda de que hay un cierto temor en Rorty a dar por buena la categoría de lo 'humano', porque su esquema liberal de pensamiento huye de toda identificación con algún modelo concreto. Pero tal recelo no es una exigencia del liberalismo. De hecho, un liberal como Mill, que tampoco está dispuesto a encorsetar lo humano en una irígida definición, se cuida mucho, sin embargo, de señalar los rasgos que definen nuestra humanidad, en concreto, nuestra libertad, nuestra posibilidad de autodeterminarnos, precisamente para reforzar su concepción liberal, esto es, para que una vida humana nunca pueda reconocerse en la vida del bruto o en la no- vida del mine$\mathrm{ral}^{7}$. De manera que el recelo de Rorty a la hora de hablar de lo humano podría volverse incluso en contra de sus pretensiones liberales, pues si nada define lo humano, cualquier forma de vida desarrollada por el hombre, incluso aquella en la que sus posibilidades quedan postradas asimilándose a la vida del animal $o$, si se nos permite, del mineral, seguirá considerándose como 'humana'.

Claro que negar ciertos rasgos definitorios de lo humano no le resulta del todo fácil a Rorty, quien apunta que aunque nada tiene una naturaleza intrínseca, y tampoco el hombre, tenemos que admitir que los seres humanos "protagonizan un conjunto peculiar de relaciones" ${ }^{8}$. Pero si no hay nada que pueda considerarse 'intrínseco', nuestras descripciones no pueden considerarse más o menos reales, sino, sencillamente, más o menos útiles. ${ }^{9}$ Mas si se pregunta '¿útiles para qué?', añadirá Rorty, sólo cabe la respuesta 'útiles para un futuro mejor', y si se pregunta ' $¿$ mejor en qué sentido?', no hay respuestas. Para el pragmatista, bueno es sólo la libertad, la variedad, el crecimiento ${ }^{10}$. Pero lo que no parece capaz de justificar el pragmatista es por qué la libertad, la variedad, el crecimiento son 'buenos'.

Por otra parte, en su crítica a la metafísica, que tiene su mayor exponente en Platón, el pragmatismo substituye el par apariencia-realidad por el de pasado-futuro, y la búsqueda del conocimiento, de la certeza, es reemplazada por la esperan$\mathrm{za}$, apareciendo como términos antitéti$\cos ^{11}$. No en vano tal disyuntiva queda plasmada en el título de la citada obra, a saber, ¿Esperanza o conocimiento? La opción de Rorty es por la esperanza, por el futuro, dejando atrás el conocimiento, la metafísica, el pasado. Pero sin entrar en mayores profundidades, hemos de apuntar que no nos parece acertada esta contraposición 
entre conocimiento y esperanza. Si atendemos al ejemplo paradigmático de Platón, modelo de pensamiento que Rorty nos invita una vez y otra a abandonar, ¿acaso no se da en él una búsqueda del conocimiento alentada por la esperanza de superar un presente insatisfactorio? ¿No es precisamente el futuro que se espera alcanzar, y nunca el pasado-presente, que desde su estupidez había condenado a Sócrates, la justificación última de una filosofía que se considera en el polo más opuesto del pragmatismo y sus esperanzas de futuro? $Y$ además, ¿cómo renunciar a la búsqueda de conocimiento cuando es en ella donde pone el filósofo todo su empeño, toda su esperanza? A pesar de todo, el pragmatismo reivindica la imaginación frente al conocimiento, y a la figura del filósofo contrapone la del poeta ${ }^{12}$. Por ello insiste en no preocuparse acerca de si nuestras ideas están bien fundadas, sino más bien en si son interesantes: "Decir que uno debe reemplazar el conocimiento por la esperanza es decir, más o menos, la misma cosa: que uno debe dejar de preocuparse por si lo que cree está bien fundado y comenzar a preocuparse por si se ha sido suficientemente imaginativo como para pensar alternativas interesantes a las propias creencias actuales." ${ }^{13}$ Pero a nosotros nos parece que todo este modo de hablar es excesivamente vago. ¿Qué significa 'una alternativa interesante'? ¿En relación a qué consideramos algo como 'interesante'? $\mathrm{Y}$ ¿se puede de veras vivir sin buscar un fundamento - todo lo abierto a revisión que se quiera- para nuestras más intimas creencias, aquellas que nos justifican?

Así que, según Rorty, no podemos escapar a nuestra contingencia, ni a la contingehia del lenguaje, ni a la contingencia de una realidad 'inapresable'. Tampoco hemos de preocuparnos de si aquello que pensamos está o no bien fundado, sino de si es o no interesante, aunque no sepamos definir lo 'interesante'. Así pues, añejos problemas como el del conocimiento y el de la posibilidad de alcanzar la verdad quedarían resumidos para Rorty en los siguientes términos: "Lo más importante que hemos aprendido de Kuhn y de Davidson es que no hay algo así como 'un orden natural de las razones' que se debe seguir para justificar creencias. No hay ninguna actividad llamada 'conocimiento' que tenga una naturaleza a descubrir y para la cual científicos naturales están específicamente dotados. Existe, sencillamente, el proceso de justificar las creencias ante la audiencia. Y ninguna audiencia está más próxima a la naturaleza ni es mejor representante que cualquier otra de algún ideal ahistórico de la racionalidad. La idea de que hay un tema de estudio llamado 'racionalidad' también se esfuma, y por las mismas razones que se esfuma la idea de que hay un tema de estudio llamado 'conocimiento'." ${ }^{4}$ En efecto, para Rorty, toda creencia está justificada desde el momento en que no hay conexión entre justificación y verdad ${ }^{15}$. Sólo hay creencias y procesos de justificación ante audiencias finitas, entre las que no hay jerarquía. No es de extrañar, pues, que con este planteamiento de 'o todo o nada', Rorty llegue a la siguiente conclusión acerca de la verdad: "Sólo habría una meta 'superior' de la indagación, llamada 'verdad', si hubiera una cosa tal como la justificación última, una justificación ante Dios o ante el tribunal de la razón, en tanto distintos de cualquier audiencia meramente finita." ${ }^{6}$ Pero para Rorty, no hay posibilidad de que haya un tribunal que tenga lo que Putnam llama ta perspectiva del ojo de Dios ${ }^{17}$. La maldición de lo finito cae, según Rorty, sobre toda audiencia posible, por amplia que sea.

De manera que, apuntará Rorty, sustituyamos el viejo par apariencia- realidad por el de pasado- futuro; concentrémonos en el futuro $\mathrm{y}$, de espaldas a una pasión inútil, la del conocimiento, abrámonos a 
la esperanza que el vuelo de la imaginación levanta. Si trasladamos estas conclusiones al ámbito moral, ya que no hay un punto de vista privilegiado, Rorty afrontará la cuestión sobre el progreso moral "como un incremento de la sensibilidad, un aumento de la capacidad para responder a las necesidades de una variedad más y más extensa de personas y cosas. Los pragmatistas no consideran el progreso científico como la atenuación gradual del velo de la apariencia que oculta la naturaleza intrinseca de la realidad, sino como la aptitud creciente de responder a las inquietudes de grupos cada vez más extensos de personas, especialmente de personas que generan las observaciones más agudas y ejecutan los experimentos más refinados. Del mismo modo, consideran el progreso moral como un estar en condiciones de responder a las necesidades de grupos de personas más y más abarcativos"18. Nuestra pregunta es, $¿$ incluiremos en este grupo también a los fanáticos y violentos? Además, hemos de apuntar que Rorty no puede justificar por qué utiliza este criterio para hablar de progreso. ¿Por qué hablar de 'incremento de la sensibilidad' y no más bien de una mayor $-i$ ilimitada?- elasticidad? Y, sin embargo, nos dice, los pragmatistas están empeñados en "la idea de abarcar a más y más seres humanos en nuestra comunidad, de tomar en cuenta los intereses y las perspectivas de un número creciente de seres humanos". ${ }^{19} \mathrm{O}$, dicho de otro modo: "Sustituyen la idea kantiana de una Voluntad Buena por la idea de un ser humano cálido, sensible y compasivo." ${ }^{20}$ Con toda franqueza, no vemos para este empeño pragmatista ningún punto de apoyo teórico que lo justifique, y más cuan: do lo que importa al pragmatista es hasta qué punto las ideas o las estrategias de acción son útiles para lidiar con las cosas y satisfacer adecuadamente nuestras necesidades $^{21}$. Pero la compasión, queremos apuntar nosotros, desborda el criterio de utilidad, está en otra órbita. Además, recordémoslo, no hay audiencias cualificadas. Sobre todas - también sobre la que aspira a ser más y más abarcativa- recae la maldición de lo finito, la maldición de no poder adoptar 'el punto de vista de Dios'. Por todo ello, creemos que, pese a Rorty, lo mejor de su propuesta es lo que en ella pervive de 'buena voluntad' kantiana, aunque carezca de justificación teórica.

\section{Rorty y los derechos humanos}

El pragmatista quiere librarse de la kantiana obligación moral incondicional, y un buen ejemplo para ello lo ofrece la problemática de los derechos humanos. Su planteamiento contrasta notablemente con el de R. Dworkin, para quien tales derechos están por encima de toda consideración de la eficiencia y la conveniencia social. Pero para Rorty, apelar a los derechos humanos como limite infranqueable para la acción equivale, ni más ni menos, a detener toda reflexión, toda crítica posible: "Desde el punto de vista del pragmatista, la noción de 'derechos humanos inalienables' no es ni mejor ni peor que el eslogan de la 'obediencia a la voluntad divina'. Cuando se los invoca como motores inmóviles, esos eslóganes son, sencillamente, una manera de decir que no va más allá, que hemos agotado nuestros recursos argumentativos. Hablar de voluntad de Dios o de los derechos del hombre, como hablar del 'honor de la familia' o de 'la patria en peligro', no es algo que resulte apropiado para la crítica y el análisis filosóficos. Es infructuoso mirar más allá de ellos. Ninguna de esas nociones debe analizarse porque todas son maneras de decir 'aquí me paro: no puedo hacer otra cosa'. No son razones para la acción, sino anuncios de que se ha pensado bien el problema y se ha tomado una decisión." 22 
Pero, tal y como a nosotros nos parece, considerar la apelación a los derechos humanos algo así como un cerrojazo a toda argumentación ulterior sólo se justifica desde su convicción de que los derechos humanos no pueden fundamentarse, a lo que se añade su opinión, que comparte con E. Rabossi, de que el problema de la fundamentación de los derechos humanos está pasado de moda ${ }^{23}$. El lenguaje de los derechos humanos guarda un sabor añejo, a metafísica rancia, $y$, al igual que la moral tradicional, "es vulnerable a las sugerencias nietzscheanas de que Dios y los derechos humanos son supersticiones, dispositivos propuestos por los débiles para protegerse de los poderosos." ${ }^{24}$ Pero el origen dudoso de tal constructo, añade Rorty, no debe hacernos dudar de su utilidad, al igual que las preocupaciones teológicas de Newton no son una objeción contra su mecánica ${ }^{25}$. Tal sería la tímida defensa que, para Rorty, cabe hacer de los derechos humanos, a saber, su utili$\mathrm{dad}^{26}$, aunque no se den razones de por qué la utilidad es un bien, ni de por qué la utilidad que incorporan los derechos humano ${ }^{27}$ ha de prevalecer, por ejemplo, sobre la utilidad del poder, o la utilidad de los intereses en juego de los más fuertes.

Parece, pues, que el lenguaje de los derechos está suspendido en la cuerda floja de las preferencias; que no hay ningún argumento que los haga firmes, que arroje sobre ellos el carácter de incondicionales, de innegociables a las presiones del interés o de la conveniencia. Para Rorty, aqui es donde está el problema, a saber, en la imposibilidad de fundamentar racionalmente tales derechos, algo que no puede hacerse ni siquiera apelando a la común necesidad de protegerse frente al dolor: "Quienes desean proporcionar fundamentos racionales, filosóficos a una cultura de derechos humanos dicen que lo que los seres humanos tienen en común sobrepasa los factores adventicios como la raza o la religión. Pero tienen problemas a la hora de decirnos en qué consiste esta comunalidad. No basta con decir que todos comparten una susceptibilidad común al dolor. Si lo que importara fuera el dolor sería tan importante proteger a los conejos de los lobos como proteger a los judíos de los nazis. Si aceptamos el enfoque naturalista, darwiniano, de los origenes humanos, no sirve decir que tenemos en común la razón, porque, en ese enfoque, ser racional es, sencillamente, ser capaz de usar lenguaje. Pero hay muchos lenguajes y la mayoría de ellos es excluyente. El lenguaje de los derechos humanos es una característica de nuestra especie, ni más ni menos que los lenguajes que insisten en la pureza racial o religiosa". 28

Pero ¿cómo puede decir Rorty que el lenguaje de los derechos humanos está al mismo nivel (es un lenguaje más) que el lenguaje racista? ¿Y cómo se puede frivolizar el exterminio judío a manos de los nazis equiparándolo al caso de los lobos y conejos? Por supuesto que hay muchos lenguajes, y que todos estarian al mismo nivel si no apelamos a lo 'humano' como criterio moral para discriminarlos. Lo "humano' frente a lo 'inhumano' tendría que seguir siendo el criterio, "la medida de todas las cosas'. El problema es que Rorty se ha quedado sin medida. Y es una lástima que después de reivindicar a Hume frente a Kant ${ }^{29}$, no sea mejor lector de Hume. Y decimos esto porque Hume dejó muy clara esa comunalidad, tan difícil de probar, según Rorty, si apelamos a la razón. Esa comunalidad la apoyó Hume en lo que podríamos acuñar nosotros una 'comunidad de corazón', que posibilita la existencia de lazos que unen, de vínculos que acortan distancias, y que en Hume tiene un nombre: sentimiento de humanidad. Basta leer sus Investigaciones sobre los principios de la moral, su mejor libro, como a Hume le gustaba reconocer, para comprender que el carácter universalista de la moral 
procede de que hay en la estructura simpática de la naturaleza humana, junto a otros sentimientos, lo que Hume llama sentimiento de humanidad (sentiment of humanity) ${ }^{30}$, que reacciona frente a la brutalidad, el sufrimiento, y todas aquellas acciones que, en el presente, o en el pasado, han atentado contra el hombre. Por eso, si el objeto de la ambición no puede ser uno, sino que entre los hombres no hay acuerdo sobre los fines que persiguen, el rechazo de la tortura, del sufrimiento, de la arbitrariedad es prácticamente unánime, y ello posibilita una moral universal. $\mathrm{O}$, por decirlo con sus propias palabras, la ambición de un hombre no es la ambición de otro, pero la humanidad de un hombre es la humanidad de $\operatorname{todos}^{31}$. El acierto de Hume es haber hecho descansar la universalidad de la moral, no como Kant, sobre una formal y fría razón universal, sino sobre la universalidad de este sentimiento de humanidad, presente en todo hombre, con independencia del tiempo y lugar. Bien es cierto que estos sentimientos de humanidad pueden ser desarrollados o asfixiados por una determinada cultura, y que, por tanto, no tienen garantizado, sin más, su futuro. Pero este es un problema que no afecta a un sentimiento que, como tal, no es un mero constructo, sino que forma parte de nuestra común y simpática naturaleza humana. Nuestro no poder ser indiferente a la suerte de los otros, nuestro no poder permanecer indiferentes al sufrimiento del otro: ahí ponía Hume su esperanza de una ética universal compatible con una pluralidad de formas de vida ${ }^{32}$.

$Y$, sin embargo, Rorty desconfía de todo universalismo. Tanto es así que, frente a 'Habermas, insiste en que no necesitamos pensar en términos universalistas ${ }^{33}$. Pero, preguntamos nosotros, ¿cómo es posible hablar de derechos humanos y no pensar en términos universalistas? Rorty lo hace. Más aún, llega incluso a reconocer expre- samente que su enfoque de los derechos humanos es antiuniversalista, "en el sentido de que desalientan los intentos de formular generalizaciones que abarquen todas las formas posibles de existencia humana. Tener esperanza en un futuro humano mejor, actualmente imaginable, es tener la esperanza de que ninguna generalización que podamos formular ahora será adecuada para abarcar el futuro" 34 . Pero por desgracia, Rorty siempre está pensando con esquemas dualistas poco flexibles. ¿Quién pretende cancelar el futuro? A nuestro juicio, se equivoca Rorty al considerar que ser antiuniversalista es el único modo de negarse a formular todas las formas posibles de existencia humana. Cabe ser universalista, en el sentido de afirmar un núcleo humano común compartido $y$, al mismo tiempo, admitir una concepción pluralista de la vida. Cabe, como piensa Habermas, diferenciar las cuestiones de justicia de aquellas otras cuestiones relativas a qué sea una vida buena. O cabe, como ha dicho Berlin ${ }^{35}$, reconocer una pluralidad de valores, de fines para la existencia, y, sin embargo, admitir la necesidad de un limite (los derechos humanos universales), transgredido el cual, ya no podemos reconocer una forma de vida como 'humana' ${ }^{36}$. $Y$, sin embargo, Rorty insiste: "Los pragmatistas sugieren, simplemente, que dejemos a un lado la búsqueda de la comunalidad." 37 Pero a tales palabras habría que responder diciendo que no parece viable defender los derechos humanos y renunciar a dicha búsqueda, a menos que queramos negar que todos los hombres sean iguales. Pero reconocer que lo que nos une al otro, con independencia de su particularidad, es nuestra común humanidad no implica de ningún modo negarnos a reconocer los distintos contextos y demandas, que requerirán una especial atención para hacer valer en la práctica aquellos derechos.

Tal vez la búsqueda de esa comunalidad, que Rorty pretende que abandone- 
mos, no de todos los frutos deseados si la emprendemos siguiendo el itinerario abierto por Kant, haciéndola descansar en la mera razón. Pero Rorty es incapaz de ver que lo que acorta las distancias entre un hombre y otro, quizás no sea tanto esa facultad llamada razón, cuanto esos sentimientos de humanidad, presentes en todo hombre, de los que nos habló Hume. Son estos sentimientos de humanidad compartidos los que levantan su dique frente a la brutalidad, la injusticia y, en definitiva, frente al sufrimiento. $Y$ la razón, algo de lo que también se olvida Rorty, se pone a trabajar según Hume para el sentimiento, a fin de que no sea victima de un engaño. La razón juega su papel, importantísimo, en la dilucidación, en la investigación de las circunstancias que rodean una acción o un hecho. Y, una vez realizadas sus pesquisas, presenta sus informes a aquél, quien dictamina, quien emite su juicio, inclinando la balanza a un lado u otro, siendo entonces los sentimientos de humanidad quienes, a la vista de tales informes, realizan la función de juez ${ }^{38}$.

De todos modos, resulta más que evidente la dificultad que el propio Rorty tiene a la hora de negarse a reconocer esa común humanidad que estrecha vínculos. El siguiente texto es prueba de esta dificultad que raya en la inconsistencia o en la terquedad de querer dar 'puntadas', como él dice, para acortar distancias y negar, a un mismo tiempo, un espacio humano común: "Convencidos de que no hay una esencia humana sutil que la filosofía podría aprehender, no tratamos de reemplazar la superficialidad con la profundidad ni elevarnos sobre lo específico para captar lo universal. Nos gustaría minimizar una diferencia por vez: la diferencia entre cristianos y musulmanes en una aldea bosnia, la diferencia entre blancos y negros en una ciudad de Alabama, la diferencia entre homosexuales y heterosexuales en una congregación católica de Quebec. Lo que esperamos es unir a esos grupos mediante un millar de 'puntadas', invocando mil cosas menudas en común entre sus miembros, en lugar de especificar una única cosa grande, su común humanidad" 39 . Rorty se nos muestra, una vez más, dualista e inflexible, a la vez que terco al no querer reconocer que esas 'mil puntadas menudas' sólo pueden darse si se reconoce un trasfondo común que las articule.

Rorty quiere apostar por la esperanza, por el futuro, pero no tiene nada en qué apoyar esta esperanza. Se autodefine como un 'ironista liberal', alguien para quien lo peor que puede haber es la crueldad $y$, al mismo tiempo, se enfrenta a la imposibilidad de fundamentar tal rechazo, tal y como se constata en el siguiente texto cuyo interés confiamos que nos disculpe de su extensión:

"Empleo el término 'ironista' para designar a esas personas que reconocen las contingencias de sus creencias y de sus deseos más fundamentales: personas lo bastante historicistas y nominalistas para haber abandonado la idea de que esas creencias y esos deseos fundamentales remiten a algo que está más allá del tiempo y del azar. Los ironistas liberales son personas que entre esos deseos imposibles de fundamentar incluyen sus propias esperanzas de que el sufrimiento ha de disminuir, que la humillación de seres humanos por obra de otros seres humanos ha de cesar.

Para el ironista liberal no hay respuestas alguna a la pregunta: '¿Por qué no ser cruel?', ni hay ningún apoyo teórico que no sea circular de la creencia de que la crueldad es horrible. Tampoco hay respuesta a la pregunta: '¿Cómo decidir cuándo luchar contra la injusticia y cuándo dedicarse a los proyectos privados de creación de sí mismo?' (...) El que cree que hay, para las preguntas de este tipo, respuestas teóricas bien fundadas - algoritmos 
para la resolución de dilemas morales de esa especie- es todavía, en el fondo de su corazón, un teólogo o un metafísico. Cree que existe, más allá del tiempo y del azar, un orden que determina el núcleo de la existencia humana y establece una jerarquia de responsabilidades" 40 .

Pero si no hay respuesta a la pregunta '¿por qué no ser cruel?', entonces no vemos lazo alguno entre ser un ironista liberal y el rechazo de la crueldad. Cabría, pues, pensar en un ironista liberal que, al carecer de fundamentos contra la crueldad, no pudiera tampoco emitir palabra alguna para rechazarla. Pues quien no tiene nada que objetar a la crueldad, ¿en qué se diferencia, a fin de cuentas, de quien abiertamente la tolera, dejando que siga su curso?

Rorty cree en la posibilidad ( a partir de su ironismo liberal?) de defender la solidaridad como eje vertebrador de su utopía liberal ${ }^{41}$. Pues bien, lo que nos parece cuestionable no es el propósito moral de trabajar por la solidaridad; lo que nos parece discutible es que se pueda 'teorizar' sobre su posibilidad desde la defensa pragmatista de un historicismo radical o fuerte como el de Rorty. Si carecemos de argumentos en contra de la crueldad, ¿por qué pretender la solidaridad y no su contrario? No que reivindiquemos la solidaridad, sino el porqué de tal demanda es lo que hace del pragmatismo de Rorty una filosofía tan contingente, tan en el aire, que hasta, si la juzgamos desde su propio criterio, dudamos de su utilidad. Dicho de otro modo, lo que cuestionamos es que sea posible apostar por un proyecto moral como es el de la solidaridad si no tenemos algo, por mínimamente firme que sea, que justifique tal apuesta. No podemos emprender un camino y no tener razones para hacerlo. Pero Rorty sostiene que hay un corte entre las convicciones filosóficas y las actividades políticas ${ }^{42}$. Por ello, el vinculo teórico, que a Rorty le parece resuel- to, entre ironismo liberal y solidaridad, no sólo no resulta claro, sino que, según nos parece a nosotros, tampoco habría argumentos suficientes que impidiesen darse la circunstancia de ser, a un mismo tiempo, un ironista liberal en la teoría y mostrarse luego alegremente insolidario en la práctica.

Alguien que, como Rorty, defiende hasta tales extremos la contingencia del lenguaje, la contingencia del yo, y que reconoce la imposibilidad de justificar teóricamente la lucha contra la crueldad o el exterminio, deberia, tal vez, elegir otro camino distinto al de la indagación filosófica, para hacer valer algo que, a nuestro juicio, y desde su esquema, no pasa de ser un mero acto de fe, tan aceptable, desde su propia óptica, como su contrario. Rorty insiste en cómo se alcanza o realiza la solidaridad ${ }^{43}$, pero no es capaz de argumentar o justificar por qué es una meta que pudiéramos considerar moralmente buena.

Pero Rorty, aferrado a la idea de la contingencia del lenguaje, insiste en la tesis de que una sociedad liberal no necesita de 'fundamentos filosóficos', sencillamente porque la idea de fundamentación es una vieja idea heredada del cientifismo de la Ilustración que es preciso superar; así, consciente de que no es posible fundamentar nada, cree tan sólo posible comparar la sociedad liberal con otros modelos. Pretender, nos advierte Rorty, construir un muro de argumentación con el que acorralar a enemigos de la sociedad liberal como, por ejemplo, los nazis, es fracasar plenamente, porque tal muro no es sino "un léxico más, una manera más de describir las cosas. El muro se convierte entonces en un telón pintado, una obra humana más, un fragmento más de decorado cultural" ${ }^{44}$. Pero aquí Rorty confunde el hecho de que todos los lenguajes sean producto humano con el de que sean cualitativamente homogéneos. Resulta inaceptable decir que los argumentos que puedan esgrimirse contra 
las atrocidades del nazismo sean 'un léxico más', o 'un fragmento más de decorado cultural'. Creemos, sin embargo, que determinados caminos pueden estar, en efecto, al mismo nivel, igual que determinadas puertas. Pero unos nos conducen hacia lugares tranquilos y otros pueden bloquearnos el paso, o incluso aniquilarnos; aun estando todos a ras del suelo, no todos son cualitativamente idénticos. Pero para Rorty, no hay ningún punto de apoyo sólido para ejercer la crítica, porque esto implicaría admitir un punto de vista privilegiado. Pero para nosotros la cuestión es mucho más sencilla que el apelar o no a puntos de vista privilegiados. Se trataría, más bien, de aceptar o no que existen el hombre y lo humano, y, por tanto, las condiciones que nos permitirian hablar de una vida, como diría Berlin, 'decente'. Y aquí nos gustaría decir, con I. Berlin, que si aceptamos la idea de que existe algo así como el 'hombre', y si aceptamos que existe algo asi como lo que cabría llamar una vida 'decente', la categoría de derechos humanos marcaria las fronteras, los límites, dentro de los cuales habría de tener lugar toda una variada gama de formas de entender la vida ${ }^{45}$. El lenguaje de los derechos, quisiéramos apuntar nosotros, no sería 'un léxico más', sino un léxico trascendental en el sentido kantiano del término: los derechos humanos serían las condiciones de posibilidad misma para toda existencia 'decente', para toda existencia que se precie de 'humana'. Los derechos humanos vendrian a constituir el tope, el limite que no puede ser transgredido por una sociedad que aspire a tal título. Pero no sólo en sentido negativo. A fin de cuentas acaban siendo los ingredientes que han de acompañar a la realización de toda forma de vida, por variada que sea, que aspire al título de 'humana'. Pero si, como a Rorty le ocurre, hemos perdido toda brújula, y ni siquiera lo humano puede ser 'la medida de todas las cosas', entonces aquellos dere- chos serán, meramente, 'un léxico más', junto al léxico que los pisotea o los viola impunemente. No nos extraña, pues, que la esperanza de Rorty no descanse en la labor de la argumentación, no descanse en la labor crítica del filósofo. No nos extraña, pues, que Rorty crea, en una de esas falsas dicotomías a las que nos tiene acostumbrados, que el filósofo, el discurso del conocimiento, haya de dejar paso al poeta (como si la poesía no fuera también otro modo de conocimiento), al discurso de la imaginación (como si el poeta solo fuera un creador de mundos imaginarios). La filosofía, según Rorty, ha de ser reemplazada por la crítica literaria ${ }^{46}$, capaz de ensanchar nuestros léxicos, de ampliar$\operatorname{los}^{47}$. Pero por nuestra parte, y sin negar el papel fundamental que la crítica literaria tiene encomendado en la búsqueda de un mundo en el que nuestras perspectivas sean menos estrechas, estamos plenamente convencidos de la imposibilidad de rehusar el análisis filosófico, la reflexión crítica, el esfuerzo argumentativo. El filósofo y el poeta viajan en la misma nave: la vida; sólo el modo en que buscan acceder al conocimiento es diverso. Pintan en el mismo lienzo, pero con materiales distintos. Por ello, no dudamos de que Dickens, en el ejemplo de Rorty, sea un aporte fundamental en la lucha por un mundo más justo $^{48}$. Pero creemos igualmente que la lucha por la justicia, en uno de sus múltiples frentes, necesita de algo más que de historias sentimentales y tristes, como Rorty las llama; necesita, más bien, integrarlas en el discurso teórico, en la argumentación y en la discusión filosófica.

Lo más decepcionante de una filosofía como la de Rorty, que parece estar ilusionada con la construcción del futuro, es precisamente su incapacidad para justificar su propia apuesta, con lo que aquella ilusión, aquella esperanza, se disipan. $Y$ todo por radicalizar su creencia en la contingencia del yo: "Nuestra insistencia en la 
contingencia, y nuestra consiguiente oposición a ideas tales como 'esencia', 'naturaleza' y 'fundamento', hacen que nos sea imposible retener la noción de que determinadas acciones y determinadas actitudes son naturalmente 'inhumanas' ". ${ }^{49}$ Ante este tipo de declaraciones no vemos cómo, honestamente, puede mantenerse en pie la esperanza. Desde este momento, Rorty se empeña en persuadirnos de que él está interesado en fomentar la solidaridad, en ampliar su radio de acción. Pero esto no le basta a quien, al margen de su eficiencia o no, espera esgrimir argumentos, razones frente a aquellos que con descaro pisotean los más elementales derechos. No nos basta el acto de fe por el cual Rorty piensa que el progreso moral consiste en ampliar la solidaridad humana, en ampliar el alcance del 'nosotros ${ }^{50}$. Rorty considera que la creencia en la idea de un componente humano central y universal llamado 'razón' es un obstáculo para la realización de su utopía liberal $^{51}$. Pero se nos ocurre lanzar contra Rorty la misma crítica que él vierte contra Kant. ¿Por qué sigue empeñado en vincular lo universal humano a la razón? ¿Por qué no ha explorado más detenidamente la vía Hume, en concreto cuando Hume hace descansar la universalidad de la moral en los sentimientos de humanidad a los que nos referíamos más arriba? Rorty se empeña en ver la solidaridad como un constructo histórico ${ }^{52}$, y no como el resultante de un sentimiento humano, tan imperecedero como el odio o el amor, y que deriva de nuestra imposible indiferencia frente al destino de los otros (simpatia), aunque, eso sí, sujeta a modulaciones culturales, haciéndose más o menos presente en determinados contextos de nuestra his-

toria. Pero entonces, el problema que nos plantea el enfoque de Rorty no es otro que el de que somos incapaces de comprender el porqué de su exhortación a ampliar el horizonte del "nosotros" ${ }^{153}$. Tal y como él aborda la cuestión, su exhor- tación a ensanchar nuestra solidaridad compite al mismo nivel con su contraria. Rorty se niega a reconocer la posibilidad de que nuestra naturaleza nos brinde un punto de apoyo, mínimamente firme, para creer en la viabilidad de tal proyecto y apostar por él. Y sin embargo, Rorty sigue empeñado en afirmar que no es posible, ni es necesario justificar el deseo de evitar la crueldad y el dolor. "A mi modo de ver, no hay nada que respalde esa exigencia, ni hay necesidad de ello" 54 , sentencia Rorty. A nuestro modo de ver, sin embargo, hay razones que avalan tal exigencia, y dar cuenta de ellas es tarea y responsabilidad del filósofo, algo que para Rorty está más que pasado de moda. En efecto, en su artículo "Derechos humanos, racionalidad y sentimentalidad", Rorty ha insistido en lo anacrónico de pretender dar una fundamentación de los derechos humanos $^{55}$. Cuestiona que nuestra 'racionalidad' pueda servir de sustento a nuestra 'dignidad', y con Rabossi cree, si atendemos a su propia declaración, "que los proyectos fundacionalistas están pasados de moda. Consideramos que nuestra tarea consiste en hacer nuestra cultura, la cultura de los derechos humanos, más consciente de sí y más poderosa, en lugar de demostrar su superioridad sobre otras culturas mediante la apelación a alguna realidad transcultural.

Pensamos que la máxima aspiración de la filosofía es compendiar nuestras intuiciones culturales sobre lo que debe hacerse en distintas situaciones" 56 .

Pero, nuevamente, tenemos que cuestionar este planteamiento. ¿Cómo puede aspirar una cultura a ser más consciente de sí renunciando a la posibilidad de justificarse racionalmente a sí misma? $Y$, por otra parte, ¿va a quedar reducida la filosofía y su actitud crítica a mero registro ${ }^{57}$ de entradas y salidas de intuiciones, a mero compendio o banco de datos? Para Rorty no existe algo así como el conocimiento 
moral, capaz de corregir nuestras intuiciones. Pero Rorty, tan dualista en sus planteamientos, vuelve a sorprendernos al desligar conocimiento moral e intuición: nuestras intuiciones morales son inatacables desde el plano del conocimiento moral. Por ello, la cuestión de si existe o no algo así como el conocimiento moral es una cuestión simplemente de eficacia, o, como a él le gusta decir, "es una cuestión de eficiencia, de la mejor manera de aprovechar la historia, de realizar la utopia de la Ilustración. Si las actividades de quienes intentan alcanzar este tipo de conocimientos parecen de poca utilidad para la realización de esta utopía, he aquí una razón para pensar que no existe tal conocimiento. Si parece que casi todo el trabajo de cambiar las intuiciones morales se efectúa mediante la manipulación de nuestros sentimientos y no del incremento de nuestro conocimiento, habrá una razón para pensar que no existe conocimiento como el que Platón, Tomás de Aquino y Kant pretendian adquirir. (...) Nosotros los pragmáticos argumentamos a partir del hecho de que la emergencia de la cultura de los derechos humanos no parece deber nada al incremento del conocimiento moral y en cambio debe todo a la lectura de historias tristes y sentimentales, y concluimos que probablemente no existe conocimiento como el que Platón contemplaba" ${ }^{58}$. Pero a nuestro juicio, Rorty cae en la fácil dicotomía 'racionalidad versus sentimentalidad', que a estas alturas ya debería haber rechazado. Ni siquiera ha aprendido, o ha querido aprender, la lección de Hume, a quien tanto nos exhorta a seguir. En efecto, Hume vio cómo todo el peso del juicio moral descansaba en el sentimiento, cómo las distinciones morales no descansan en la razón; pero insistió, y merece la pena subrayarlo, en que no hay conflicto entre la razón y la pasión ${ }^{59}$, en el sentido de que la razón trabaja al servicio de la pasión ${ }^{60}$ : la razón realiza sus pesquisas, sus inda- gaciones e informes, siendo luego el sentimiento quien, a la vista de los mismos, juzga en un sentido $u$ otro ${ }^{61}$. Sorprende, pues, ahora, el dualista planteamiento de Rorty, quien nos presenta un conocimiento desligado del sentimiento, algo que, ni siquiera Hume, aunque diferenciándolos, admitió.

Por tanto, no vamos a negar el desacierto de Kant al escindir escrupulosamente el plano de la sentimentalidad del de la moralidad. Pero igualmente inoportuno se nos antoja la expulsión de la racionalidad que ahora Rorty realiza ${ }^{62}$. Y parece que como, desde su óptica, es más eficaz, para manipular sentimientos, contar historias tristes y sentimentales, la filosofía debe dejar su puesto a la narración de estas historias $^{63}$. Pero resulta increíble que Rorty no vea cómo quedamos en brazos del azar, y cómo esta 'educación sentimental' puede invertir su signo y perder por tanto la efectividad que tanto le preocupa, si carecemos de apoyos reflexivos, teóricos, que la sustenten. Rorty parece no ver el peligro, en lo referente a la manipulación de sentimientos, que los fanatismos o los juegos de poder han supuesto a lo largo de la historia para la cultura de los derechos humanos. A su miopía o a su terquedad cabe, pues, atribuir el que Rorty nos haga estas cruciales preguntas: “ $¿$ Por qué el conocimiento se ha tornado mucho menos importante para nuestra propia imagen que hace dos siglos? ¿Por qué la tentativa de sustentar la cultura en la naturaleza y la obligación moral en el conocimiento de los universales transculturales nos parece mucho menos importante que en la Ilustración? ¿Por qué, en suma, la filosofía moral se ha convertido en una parte tan discreta de nuestra cultura?"64 A nuestro juicio, parece que Rorty quisiera firmar el acta de defunción de la filosofia. Y sin dudar, por nuestra parte, lo más mínimo de la efectividad y de la conveniencia de la literatura y de la crítica literaria en 
el trabajo por una ampliación de la cultura de los derechos humanos, la labor de argumentación y crítica del filósofo se nos antoja irrenunciable, si es que no hemos renunciado también nosotros al carácter reflexivo de la praxis. Pero entonces dudamos mucho de la efectividad de semejante práctica, al situarnos al mismo nivel de los que vociferan interesadamente, o trabajan en silencio, en contra de la expansión de semejante cultura. Si renunciamos a la tarea crítica, si solo nos contentamos con registrar y compendiar; si obviamos la tarea filosófica de búsqueda de una fundamentación de los derechos humanos, nos quedamos huérfanos de razones para luchar en su pro: quedaremos situados al nivel de los que gritan en su contra o los pisotean impunemente, haciéndole, de este modo, y contra los pronósticos de Rorty, un muy flaco favor, y haciéndolo, en cambio, a quienes son capaces de gritar más fuerte o de segar, de un tajo, toda voz. Creemos, por tanto, necesario integrar todo el aporte sentimental, hondo, del arte en el caudal de la reflexión filosófica, de la argumentación; es preciso no enfrentar más al poeta y al filósofo, sino más bien asimilar el conocimiento que el arte nos brinda sin renunciar por ello a las exigencias de la argumentación.

$Y$, sin embargo, quizás Rorty tenga razón cuando dice que con gente como Trasímaco o Calicles poco puede hacer la filosofía moral ${ }^{65}$. Pero creemos que puede contribuir muy eficazmente a que no se facilite el surgimiento de tipos así. Y creemos que la filosofía tiene una importante tarea que realizar a la hora de disipar prejuicios y fanatismos que impidan reconocer a los 'negros' o a los 'musulmanes' sen-

cillamente como humanos. No podemos dejarlo todo en manos de la 'manipulación de los sentimientos', como quiere el bienintencionado Rorty, precisamente porque las historias sentimentales y tristes no son las únicas capaces de manipular los sentimientos. También los intereses en juego son capaces de ello, y la historia es una prueba contundente. Todas estas razones nos llevan, pues, a distanciarnos de sus palabras: "Para hacer que los blancos sean más amables con los negros, los hombres con las mujeres, los serbios con los musulmanes o los heterosexuales con los homosexuales, para hacer que nuestra especie se una en lo que Rabossi llama una comunidad planetaria regida por una cultura de los derechos humanos, no sirve de nada decir con Kant: advierte que lo que tienes en común, tu humanidad, es más importante que estas triviales diferencias. Pues las personas a las que tratamos de convencer responderán que no advierten nada parecido. Estas personas se sienten moralmente ofendidas por la sugerencia de tratar a alguien que no es de la familia como si fuera un hermano, a un negro como si fuera un blanco, a un marica como si fuera normal o a un infiel como si fuera creyente." ${ }^{66}$ Pero nosotros vemos este asunto de un modo muy distinto al que está empleando Rorty. Puede, en efecto, que si nos encontramos frente a un fanático, nuestros argumentos sirvan de poco ante quien, de entrada, se niega a razonar abierta y críticamente. Pero estamos seguros de que nuestros argumentos sobre la humanidad del negro, del musulmán o del homosexual no caerán en saco roto: abonarán un campo donde el fanatismo y la intolerancia lo tengan más difícil. Y, sin embargo, quizás no le falte razón a Rorty en algo: en el diagnóstico de las causas que dan lugar a la violencia, la intolerancia, la xenofobia, a saber, un déficit en la educación, un déficit de seguridad, autoestima y simpatía ${ }^{67}$. Tampoco vamos a cuestionar que para poner freno a estas actitudes haga falta llevar a cabo, de la mano de Hume, una educación sentimental, un progreso en los sentimientos. $\mathrm{Ni}$, por supuesto, se nos ocurre cuestionar lo más mínimo la aportación fundamental que a tal progreso pro- 
porciona el arte. Pero nos parece un planteamiento miope, errado y torpe enfocarlo como una estrategia contra la razón y sus posibilidades emancipatorias, antes que reconocer la necesaria integración de sentimentalidad y racionalidad. Tal vez tenga razón Rorty al decir que el problema de la acción, del movernos a actuar, resulte más fácil a partir de historias tristes y sentimentales ${ }^{68}$. Pero ese movimiento necesita, junto a una mayor justicia material de la reflexión, del debate abierto, de la crítica y la argumentación. No podemos olvidar, pese a Rorty, la distinción kantiana entre discernimiento moral y ejecución $n^{69}$, es decir, entre saber cómo obrar, qué debo hacer, y hacerlo. De lo contrario, nuestro hacer, por eficaz que sea, será tan ciego, tan desabrigado de razones como el del asesino en masa, el torturador o el fanático. Si como dice Rorty, en este caso frente a Nietzsche, no estamos autorizados a dar la espalda al proyecto de la Ilustración ${ }^{70}$, la filosofía, que habrá de integrar el discurso del sentimiento y de la razón, que habrá de ser permeable a la educación sentimental que el arte le brinda, sin renunciar a las justificaciones teóricas, a las argumentaciones, y que, finalmente, habrá de articular la aspiración a la felicidad y a la justicia, seguirá siendo irrenunciable, y todo porque, desde su vocación emancipadora, no vemos cómo privar de actualidad a aquellas palabras de la Apología con las que Platón inmortalizó a Sócrates como símbolo de la actitud filosófica, a saber, que una vida sin análisis no merece la pena ser vivida.

\section{NOTAS}

1 "Mis ensayos deben entenderse como muestras de lo que un grupo de filósofos italianos actuales han denominado 'pensamiento débil' - reflexión filosófica que no intenta una crítica radical de la cultura contemporánea ni intenta refundarla o remotivarla, sino que simplemente recopila recordatorios y sugiere algunas posibilidades interesantes." Rorty, R., Ensayos sobre Heidegger y otros pensadores contemporáneos, Barcelona, Paidós, 1993, p. 22.

${ }^{2}$ Rorty, R., ¿Esperanza o conocimiento? Una intro ducción al pragmatismo, Buenos Aires, FCE, 1997

${ }^{3}$ Para un mayor desarrollo, cfr. ibíd. , cap. 2 , "Un mundo sin substancias o esencias".

4 Ibid. p. 46.

${ }^{5} \mathrm{Cfr}$. Hume, D., Investigación sobre los principios de la moral, ed. de Gerardo López Sastre, Madrid, Espasa- Calpe, 1991, Secc. I, p. 31.

${ }^{6}$ Rorty, R., ¿Esperanza o conocimiento? Una introducción al pragmatismo, p. 50

7 Cfr. Mill, J.S., El utilitarismo, Madrid, Alianza editorial, 1984, capitulos 1 y 2 , donde sus reflexiones morales están estrechamente ligadas a su muy bien explicitada concepción antropológica.

${ }^{8}$ Rorty, R., ¿Esperanza o conocimiento? Una introducción al pragmatismo, p. 68

${ }^{9}$ Cfr. ibíd., p. 65.

so Cfr. ibíd., pp. 14- 15

11 Cfr. ibid., p. 21
12 Para Rorty, el Filósofo ha de ser sustituido por el crítico cultural, el novelista o el poeta. El mundo es mera creación, mera fabulación de nuestro lenguaje (Cfr. Rorty, R., Contingencia, ironia, solidaridad, Barcelona, Paidós, 1991, p. 47). Es necesario reemplazar la Fïlosofia por la filosofía (Cfr. Rorty, R., Consecuencias del pragmatismo, Madrid, Tecnos, 1996, p. 21). De este modo nos abrimos a una cultura postfilosófica donde la filosofía sustituye a la Filosofía, siendo ya solo la aprehensión en conceptos de la propia época, cuya tarea fundamental consiste en describir cómo las cosas se relacionan entre sí (Cfr. ibid., pp. 51-57). Y si nos preguntamos cuál es el lugar de la filosofía en el conjunto de la cultura, la respuesta no es sino la de continuar la labor de la literatura y de las ciencias sociales. La filosofia no necesita hacer una crítica radical. No tiene que denunciar los fundamentos falsos de esta sociedad, sino contraponer sus rasgos buenos y malos (Cfr. Rorty, R., Ensayos sobre Heidegger y otros pensadores contemporáneos, pp. 43-45). Para Rorty es necesario borrar la distinción entre filosofia y literatura, y considerar a la filosofía como un género literario más (cfr. ibíd., p. 151). Es preciso abandonar el viejo sueño de la Filosofía, a saber, encontrar la única metáfora verdadera (cfr. ibid., p. 134). Y frente a la vieja mania de buscar 'argumentoș' bașta con mostrar un repertorio más variado y amplio de alternativas (cfr. ibíd. p. 171). No nos sorprende, pues, que Rorty ironice, 
con una exageración, a nuestro juicio, calculada, contra los profesores de filosofia: "Aún se pueden encontrar profesores de filosofia que te dicen solemnemente que están buscando la verdad, y no solo un relato o un consenso sino una representación auténtica, manejable y exacta de la forma de ser del mundo." (Ibid., pp. 126-127). A nuestro juicio, el antiplatonismo de Rorty acaba cometiendo la misma injusticia con la Filosofia que Platón cometió contra la Poesía; y tal vez no se trate de invertir a Platón, sino de acercar, integrar, estrechar los ámbitos de lo literario y de lo filosófico, sin perder de vista sus diferencias.

${ }^{13}$ Rorty, R., ¿Esperanza o conocimiento? Una introducción al pragmatismo, p. 27.

14 Ibíd., p. 32

${ }^{15}$ Cfr. ibid., pp. 34- 35.

${ }_{16}$ Ibíd., p. 35.

${ }^{17}$ Cfr. ibid., p. 36.

${ }^{18}$ Ibíd., p. 91

19 Ibid., p. 92.

20 Ibíd. p. 94

${ }^{21}$ Cfr, ibid., pp. 77- 78.

${ }^{23}$ Ibíd, p. 95.

${ }^{23}$ Cfr. Rorty, R., "Derechos humanos, racionalidad y sentimentalidad", en Shute, S., y Hurley, S., De los derechos humanos, Barcelona, Trotta, 1998, pp. 117- 136 , p. 120

${ }^{24}$ Rorty, R. ¿Esperanza o conocimiento? Una introducción al pragmatismo, p. 95.

${ }^{25}$ Cfr. ibid., p. 96.

${ }_{26}$ "Las ideas se clasificarán de acuerdo con su utilidad relativa más que en función de sus fuentes". Ibíd. , p. 96 .

${ }^{27} \mathrm{Se}$ refiere a ella, más adelante, del siguiente modo: "Debatir la utilidad del conjunto de constructos sociales que llamamos 'derechos humanos' es debatir la cuestión de si las sociedades incluyentes son mejores que las excluyentes. Y esto es debatir la cuestión de si las comunidades que alientan la tolerancia ante el desviacionismo inocuo deben ser preferidas a aquellas comunidades cuya cohesión social depende de la conformidad o de mantener a distancia a los de afuera o de eliminar a los que tratan de corromper a la juventud." Ibid., p. 98. El problema es que no es posible para Rorty un debate racional sobre 'lo mejor' en cuanto que ni siquiera 'lo humano' se permite que sea 'la medida de todas las cosas', sino que este 'lo mejor' quedará, en última instancia, a merced del más fuerte. $Y$ de hecho esto se desprende de sus propias palabras cuando escribe: "Lo único que justifica una mutación

- biológica o cultural, es su contribución a la existencia en algún lugar del futuro, de una especie más compleja e interesante. La justificación es siempre una justificación desde el punto de vista de los sobrevivientes, de los vencedores. No hay un punto de vista que esté por encima del de ello. Esto equivale en el campo de las ideas a la verdad de que el poder hace a lo justo y de que la justicia es el interés del más fuerte." Ibíd. , p. 14.

${ }^{28}$ Ibid., p. 99

${ }^{29}$ Cfr. Rorty, R., "Derechos humanos, racionalidad y sentimentalidad", pp. 131- 136.

${ }^{30} \mathrm{Cfr}$. Hume, D., Investigación sobre los principios de la moral, Sección IX, pp. 144- 145

31. Por su importancia, nos parece conveniente traer aquí el texto de Hume al que nos estamos refiriendo y en el que nos dice cuál es el fundamento de la moral: " $\mathrm{Y}$ aunque no se puede considerar generalmente que este sentimiento de humanidad sea tan fuerte como la vanidad o la ambición, sin embargo, al ser común a todos los hombres, sólo él puede ser el fundamento de la moral o de un sistema general de censura o alabanza. La ambición de un hombre no es la ambición de otro; y el mismo acontecimiento u objeto no resultará satisfactorio para ambos. Pero la humanidad de un hombre es la humanidad de todos, y el mismo objeto afecta a esta pasión en todas las criaturas humanas." Ibid., Sección IX, p. 145

${ }^{32}$ Cfr. "Un diálogo", incluido en Hume, D., Investigación sobre los principios de la moral, pp. 202-222, donde se aborda especialmente esta problemática.

${ }^{33}$ Cfr. Rorty, R., ¿Esperanza o conocimiento? Una introducción al pragmatismo, p. 99, nota 19.

${ }^{4}$ Ibid., p. 99.

${ }_{35}$ No deja de ser llamativo cómo Rorty intenta rentabilizar al pluralista Berlin para escudarse en él y eludir las acusaciones de relativismo (Cfr. Rorty, R., Contingencia, ironia, solidaridad, pp. 64-67, y p. 73), sólo que Rorty no ha sabido ver que lo que evita el relativismo en Berlin es, precisamente, el reconocimiento de un límite para lo humano, un limite, en definitiva, para la variedad, para el crecimiento, más allá del cual ya no es posible ir, a menos que pretendamos abandonar el horizonte humano. Veamos, como excelente ejemplo de ello, el siguiente texto de Berlin: "Las formas de vida difieren. Los fines, los principios morales son muchos. Pero no infinitos: han de estar dentro del horizonte humano. Si no lo están, quedan fuera de la esfera humana." Berlin, I., El fuste torcido de la humanidad. Barcelona, Peninsula 1992, p. 30. Por nuestra parte nos hemos ocupado de esta cuestión en "El universalismo trágico de Isaiah Berlin", Laguna, $\mathrm{n}^{\circ}$ extraordinario, 1999, pp. 147-157. Merece subrayarse aquí el Prólogo que Salvador Giner dedica a El fuste torcido de la humanidad, en el que se refiere conjuntamente a la común humanidad y al pluralismo berliniano (pp. 5- 14). Destacables son, igualmente, en la medida en que abundan y profundizan en esta cuestión, los trabajos de Badillo O' Farrell, P., "Pluralismo, libertad, decencia. Consideraciones en torno a la Filosofía política de Isaiah Berlin", y García Guitián, E. "El pluralismo liberal de I. Berlin ", en Badillo $O^{\prime}$ Farrell, P. y Bocardo Crespo, E., (eds.), Isaiah Berlin. La mirada despierta de la historia, Madrid, Tecnos, 1999, pp. 153-183, 293-308, respectivamente. 
${ }^{36}$ Merece la pena traer aquí un texto de Berlin cuya importancia para el tema que estamos tratando esperamos que nos disculpe de su extensión: "Si encontramos individuos que simplemente discrepen de los otros respecto a los fines de la vida, que prefieren la felicidad a la abnegación, o el conocimiento a la amistad, les aceptamos como seres humanos semejantes a nosotros, porque su concepción de lo que es un fin, los argumentos que esgrimen para defender sus fines, y su comportamiento general, entran dentro de los límites de lo que consideramos humano. Pero si encontramos a alguien que no puede entender por que (por utilizar un ejemplo famoso), no debería destruir el mundo para aliviar un dolor en su dedo meñique $o$ alguien que no ve realmente que haya nada de malo en condenar al inocente o traicionar a amigos o tortura a niños, nos encontramos con que no podemos discutir con gente así, no tanto porque nos horrorice como porque pasamos a considerarlos en cierto modo inhumanos: los llamamos idiotas morales. A veces los encerramos en manicomios. Están fuera de las fronteras de la humanidad en el mismo grado en que 10 están las criaturas que carecen de alguna de las caracteristicas físicas mínimas que conforman a los seres humanos." Berlin, I., El fuste torcido de la humanidad, Barcelona, Península, 1992, p. 192

${ }^{37}$ Rorty, R., ¿Esperanza o conocimiento? Una introducción al pragmatismo, p. 99.

${ }^{38} \mathrm{Cfr}$. Hume, D., Investigación sobre los principios de la moral, Secc. I, p. 35.

${ }^{39}$ Rorty, R., ¿Esperanza o conocimiento? Una introducción al pragmatismo, p. 100.

${ }^{40}$ Rorty, R., Contingencia, ironía, solidaridad, p. 17

1 Cfr., ibid., p. 18.

${ }^{42}$ Cfr. ibid. pp. 15-17.

43 "En mi utopía, la solidaridad humana no apareceria como un hecho por reconocer mediante la eliminación del 'prejuicio' o yéndose a esconder a profundidades antes ocultas, sino, más bien, como una meta por alcanzar. No se ha de alcanzar por medio de la investigación, sino por medio de la imaginación por medio de la capacidad imaginativa de ver a los extraños como compañeros en el sufrimiento. La solidaridad no se descubre, sino se crea, por medio de la reflexión. Se crea incrementando nuestra sensibilidad a los detalles particulares del dolor y de la humillación de seres humanos distintos, desconocidos para nosotros. Una sensibilidad incrementada hace más dificil marginar a personas distintas a nosotros, pensando: 'No lo sienten como lo sentiriamos nosotros', o 'Siempre tendrá que haber sufrimiento, de modo que $\iota$ por qué no dejar que ellos sufran?' ". Ibíd. , p. 18.

${ }^{44}$ Ibid., p. 72

${ }^{45}$ I. Berlin, en diálogo con Ramin Jahanbegloo, ha realizado estas declaraciones: "Si usted me pregunta por qué creo en los derechos humanos, puedo decirle que porque es la única forma decente -e incluso tolerable- de que los humanos vivan juntos: y si me pregunta qué significa 'decente', puedo decirle que es el único tipo de vida que los humanos deben seguir si no quieren destruirse unos a otros. (...) Creo apasionadamente en los derechos humanos; esto deriva de muchas otras cosas que aceptamos todos, no es demostrable a priori. Por supuesto, no niego que existan principios generales de conducta y actividad humana sin los cuales no puede haber una sociedad mínimamente decente. No me pregunte qué entiendo por decente Por decente entiendo decente; todos sabemos qué quiere decir." Berlin, I. , Isaiah Berlin en diálogo con Ramin Jahanbegloo, Madrid, Anaya \& Mario Muchnik 1993, pp. 150-151. Para Berlin los derechos humanos forman parte de ese conjunto de creencias universales que no necesitan justificación en el sentido de que son ellas las que, por su carácter básico, justifican lo demás. Por ello no se llega a ellos a priori, a través de ningún ojo mágico racional, pero están ahí, de facto (cfr. ibid., p. 149), justificando otras normas, y englobando lo que Berlin llama 'creencias humanas universales' (cfr. ibíd. 151). Tal vez, sì indagamos los valo res vertebradores de los derechos humanos cabría explicitar el contenido de lo que cabe entender por 'decencia'. En este sentido, nos parece muy oportuno hablar de dignidad, libertad e igualdad como los tres pilares sobre los que se sustentan los derechos humanos, tal y como ha hecho A. E. Pérez Luño en su trabajo "Sobre los valores fundamentales de los derechos humanos", en Muguerza, J. y otros, El fundamento de los derechos humanos, ed. de G. Peces Barba, Madrid, Debate, 1989, pp. 279-289.

${ }_{46}$ Este cambio del filósofo por el poeta o por e crítico literario lo justifica Rorty asi: " Los ironistas leen a los críticos literarios y los toman como informadores morales, sencillamente porque tales críticos tienen una gama de relaciones excepcionalmente amplia. Son informantes morales no porque tengan un acceso especial a la verdad moral, sino porque han estado por todas partes. Han leido más libros, y por eso se hallan en mejores condiciones para no ser atrapados por el léxico de un solo libro". Rorty, R., Contingencia, ironía, solidaridad, p. 98. Desde luego, sin negar el valor que la literatura ofrece para la reflexión moral, no vemos por qué el filósofo no ha de gozar de los mismos atributos que el crítico literario.

${ }^{47}$ Cfr. ibid., pp. 98-99.

${ }^{48} \mathrm{Cfr}$. Rorty, R., Ensayos sobre Heidegger y otros pensadores contemporáneos, pp. 101-121.

${ }^{49}$ Rorty, R., Contingencia, ironia, solidaridad, p. 207

${ }^{50}$ Cfr. ibid. p. 210.

${ }^{51}$ Cfr, ibid. p. 212

${ }^{52}$ Cfr. Ibid., p. 213

${ }^{53}$ Cfr. ibid., p. 214

${ }^{54}$ Ibid., p. 216

${ }^{55}$ Rorty, R., "Derechos humanos, racionalidad y sentimentalidad", p. 120. Por nuestra parte, y sin negar con Bobbio, que el verdadero problema jurídico-político es el de la protección de los derechos, como filósofos tenemos pendiente el problema de su fundamentación. Por ello, nos parece muy oportuno e 
ilustrativo el ejemplo que pone F. Puy en su trabajo "¿Qué significa fundamentar los derechos humanos?", cuando reproduce la siguiente parábola, precisamente contestando a la negativa de Bobbio a reconocer tal necesidad teórica: " " Un hombre le pidió al Mulláh Nasrudín enseñanza espiritual. El Mulláh le dijo: "Empezaré por los fundamentos". Pero el hombre le dijo: "Déjate de preliminares. No me importan Vamos al grano rápido." El Mulláh, entonces, trajo una tinaja desfondada y empezó a echar cubos de agua en ella. Y preguntó el hombre: "Pero, ¿qué estás haciendo?" Y contestó el Mulláh: "Llenando la tinaja", $Y$ dijo el hombre: "Pero esa tinaja no tiene fondo". Y respondió el Mulláh: "A mí no me interesa el fondo. Dime cuándo llega el agua arriba nada más." Fin de la parábola. Lo que a mí me dice es esto: que en materias ético-jurídico-políticas al menos, siempre hay que ocuparse de los fundamentos. " Puy, F., "¿Qué significa fundamentar los derechos humanos? ", en Muguerza, J., y otros, El fundamento de los derechos humanos, pp. 289-302, p. 291.

${ }^{56}$ Rorty, R., "Derechos humanos, racionalidad y sentimentalidad", en Shute, S., y Hurley, S., De los derechos humanos, p.121.

${ }^{57}$ Es lo que nos queda, y Rorty mismo lo ha reconocido, cuando la filosofía no puede aspirar a la crítica. $Y$ de aquí vienen las quejas de Habermas. En efecto, el problema, tal y como muy bien lo ha precisado J. Muguerza, queda planteado en estos términos: " Como quiera que sea, lo que Rorty fustiga no es tan sólo el prurito producido por la preocupación acerca de cómo rellenar la oquedad abierta en la cultura occidental tras la volatización de la religión, sino el producido por la aparente necesidad de distinguir entre consenso fáctíco o 'convención' y 'consenso racional' o contrafáctico; 0 , si lo preferimos decir en estos otros términos, entre cuestiones de poder y cuestiones de validez. Que era, como recordarás, la distinción que se ventilaba en la polémica de Habermas con los postmodernos. Pues, efectivamente, Habermas advierte que si no hay posibilidad de distinguir entre argumentos que sean 'válidos' y argumentos que simplemente son 'aceptados por una comunidad' en tal o cual contexto sociohistórico, tampoco la habrá de abordar una crítica racional de las instituciones existentes dentro de dicha comunidad y dicho contexto." Muguerza, J., Desde la perplejidad, Madrid, FCE, 1990, p. 31.
${ }^{58}$ Rorty, R., " Derechos humanos, racionalidad y sentimentalidad", pp. 122-123.

${ }^{59}$ Cfr. Hume, D., Tratado de la naturaleza humana ed. de Félix Duque, Madrid, Tecnos, 1988, Libro II Parte III, Sección III, p. 563.

ofr. ibid., Libro II, Parte III, Sección III, p. 561.

${ }_{61}$ "Es probable que la sentencia definitiva que declara a los caracteres y a las acciones agradables u odiosas, dignas de elogio o censurables; (...) es probable - digo que este juicio definitivo dependa de algún sentido interno o sentimiento que la naturaleza ha hecho universal para toda la especie. Porque, ¿que otra cosa puede tener una influencia de este tipo? Pero con vistas a preparar el terreno para un sentimiento tal, y proporcionarle un discernimiento adecuado de su objeto, a menudo encontramos que antes es necesario realizar muchos razonamientos, hacer distinciones sutiles, obtener conclusiones correctas, realiza comparaciones entre cosas distantes, examinar relaciones complicadas y descubrir y determinar hechos generales." Hume, D., Investigación sobre los principios de la moral, Secc. I, p. 35

2 Cfr. Rorty, R., "Derechos humanos, racionalidad y sentimentalidad", p. 126.

${ }^{63}$ Cfr. ibíd., 126- 127.

64 Ibid., p. 124

${ }^{65}$ Ibid., p. 127

${ }_{66}$ Ibíd, pp. 128-129.

67 "Por seguridad me refiero a condiciones de vida suficientemente libres de riesgo como para que las diferencias con los demás resulten irrelevantes para la autoestima y la dignidad personal. (...) La seguridad y la simpatía van juntas, por las mismas razones que la paz y la prosperidad económica van juntas. Cuanto más duras son las cosas o más miedo se siente o más peligro se experimenta, menos tiempo y esfuerzo puede dedicarse a pensar en la condición de las personas con las cuales no te identificas de inmediato. La edu cación sentimental funciona únicamente cuando las personas pueden relajarse lo suficiente como para escuchar." Ibid., p. 131.

${ }^{68}$ Cfr. ibid., p. 134

69 Nos hemos ocupado de tal asunto en "Discerfímiento y ejecución en la ética de Kant. A propósito de los límites de la autonomía en el marco de la mera razón ". Pensamiento, vol. 54, $\mathrm{n}^{\circ}$ 210, pp. 397- 415, 1998.

${ }^{70} \mathrm{Cfr}$. Rorty, R., "Derechos humanos, racionalidad y sentimentalidad", p. 133. 